\title{
Personally meaningful recovery in people with psychological trauma: initial validity and reliability of the Individual Recovery Outcomes Counter (I.ROC)
}

Bridey Rudd

Thanos Karatzias

Aoife Bradley

Claire Fyvie

Scott Hardie

This is the peer reviewed version of the following article:

Rudd, B., Karatzias, T., Bradley, A., Fyvie, C. \& Hardie, S. (2019) 'Personally meaningful recovery in people with psychological trauma: initial validity and reliability of the Individual Recovery Outcomes Counter (I.ROC)', International Journal of Mental Health Nursing.

which has been published in final form at doi: https://doi.org/10.1111/inm.12671

This article may be used for non-commercial purposes in accordance with Wiley Terms and Conditions for SelfArchiving 
Title: Personally meaningful recovery in people with psychological trauma: Initial validity and reliability of the Individual Recovery Outcomes Counter (I.ROC)

Authors: Bridey Rudd, Thanos Karatzias, Aoife Bradley, Claire Fyvie, Scott Hardie

\section{Author Details:}

Dr Bridey Rudd ${ }^{1,2}$; Penumbra; (t): 01314752577 (e): bridey.rudd@ penumbra.org.uk Twitter: @ BrideyRudd; ORCiD: 0000-0003-4245-6578

Professor Thanos Karatzias ${ }^{3,4}$ : Edinburgh Napier University (t): 01314555345 (e): t.karatzias@ napier.ac.uk Aoife Bradley³ : Edinburgh Napier University (t): 01314553431 (e): a.bradley@napier.ac.uk

Dr Claire Fyvie ${ }^{4}$ : Rivers Centre (t): 01314517400 (e): claire.fyvie@ nhslothian.scot.nhs.uk

Dr Scott Hardie ${ }^{1}$ : Abertay University (t): 01382308587 (e): $\underline{\text { s.hardie@ abertay.ac.uk }}$

\section{Affiliations:}

${ }^{1}$ Department of Psychology, Abertay University, 1 Bell Street, Dundee, UK, DD1 $1 H G$

${ }^{2}$ Penumbra, Norton Park, 57 Albion Road, Edinburgh, UK, EH7 5QY

${ }^{3}$ School of Health and Social Care, Edinburgh Napier University, Sighthill Campus,

Edinburgh, UK, EH11 4BN

${ }^{4}$ NHS Lothian, Rivers Centre, Fountainbridge Library Building, 137 Dundee Street, Edinburgh, UK, EH11 $1 B G$

\section{Authorship statement:}

All authors listed meet the authorship criteria according to the latest guidelines of the International Committee of Medical Journal Editors, and all authors are in agreement with the manuscript. TK and AB planned the study; CF collected the data; AF and BR analysed the data; all were involved in writing and revising the manuscript.

\section{Address for Correspondence:}

Bridey Rudd,

Penumbra

Norton Park

57 Albion Road

Edinburgh

EH7 5QY 
Bridey.rudd@ @enumbra.org.uk

$(+44)(0) 1314752586$

\section{Acknowledgements:}

We would like to thank all the NHS clinical staff, the participants, and the wider research team at Edinburgh Napier University, Abertay University and Penumbra for their contributions to the study

\section{Disclosure statement:}

This research did not receive any specific grant from funding agencies in the public, commercial, or not-for-profit sectors. The lead author, BR is employed by Penumbra, a not-for-profit organisation whose product, I.ROC is the subject of this paper.

\section{Declaration of Ethical Approval}

This project involved a secondary-analysis of anonymised routinely collected data from the wider study 'Group Compassion Focused Therapy vs Group Psychoeducation for Adult Survivors of CPTSD, which was reviewed and approved by the South East Scotland Research Ethics Service (NR/1502AB7). All participants provided signed consent for their data to be used during this wider study. Clinical governance approval for use of anonymised data from the wider study was granted by NHS Lothian (email communication with Andrew Watson, NHS Lothian, 17/5/2017), and individual consent for use of the data in the current analysis was therefore not needed. Ethical approval was further granted for this study by the School of Social and Health Sciences' ethics committee at Abertay University (study reference number 855).

\section{Word count: 4443}




\section{Personally meaningful recovery in people with psychological trauma: Initial validity and reliability of the Individual Recovery Outcomes Counter (I.ROC)}

I.ROC is a brief tool measuring personal recovery designed for collaborative use within support. This study aimed to investigate the psychometric properties of a self-report version of the I.ROC within a trauma population. A total of 107 adults attending trauma interventions in an NHS service in Scotland completed I.ROC alongside measures of self-esteem, mental illness symptoms and functional impairment. Scores on each measure were compared to evaluate the convergent validity of I.ROC. Internal consistency and factor analytical techniques were also used to assess the structural validity and reliability of the measure. Results of internal consistency, convergent validity and factor analysis provide preliminary support for I.ROC's validity within a trauma population Previously proposed models were a poor fit for the current sample; principal components analysis suggested a threefactor structure with acceptable internal consistency, comprising ten of the original twelve items (I.ROC-10). Correlations with all measures reached significance for the original and modified I.ROC and its subscales. I.ROC appears to be a valid and reliable tool for use in measuring recovery within a trauma population, but further research is needed to examine the structural validity of I.ROC.

Keywords: recovery, mental health, trauma, outcomes, measurement, psychometrics 


\section{Introduction}

Clinical definitions of recovery referring to the remission of symptoms of mental illness and a return to pre-illness levels of functioning still dominate within many areas of mental health care, including psychological trauma services (Chouliara et al., 2011). Growing interest in a second definition of recovery drawing from the personal narratives of people who have experienced mental health difficulties (personal recovery), now challenges this dominance. Although most commonly applied within the context of mental illness, the concept of personal recovery is relevant to anyone who has experienced devastating and life-altering events (Perkins \& Repper, 2015). As such, it is inextricably linked to the concept of trauma.

Trauma "results from an event, series of events, or set of circumstances that is experienced by an individual as physically or emotionally harmful or life threatening and that has lasting adverse effects on the individual's functioning and mental, physical, social, emotional or spiritual well-being." (Substance Abuse and Mental Health Services Administration 2014: p. 7). Trauma is understood to be both a cause and a consequence of mental ill health. Although estimates vary according to methodological differences in diagnostic and measurement criteria (Mills et al, 2011), exposure to trauma (particularly during childhood) has consistently been found to increase the likelihood of developing a mental health problem (Lewis et al., 2019). It has been estimated that up to $90 \%$ of people accessing mental health inpatient services are trauma survivors (Mueser et al., 1998), yet service use remains low amongst trauma survivors (McChesney et al., 2015). Recognition of the link between trauma and mental ill health has resulted in a wealth of new trauma-informed approaches to mental health care (for a review, see Muskett, 2013), which are considered to complement models of recovery-oriented practice (Bassuk et al., 2017).

Models of personal recovery from a mental illness and trauma perspective show considerable overlap. Within mental health, personal recovery is acknowledged to be a subjective experience comprising key themes of Connectedness, Hope, Identity, Meaning and Empowerment (CHIME; Leamy et al., 2011). CHIME themes are widely endorsed, although recent research reveals cultural and population-specific variation in emphasis (van Weeghel et al., 2019), as well as the need to include further themes such as Difficulties, Therapeutic input, Acceptance/mindful awareness and Normality (returning to/desiring) to more fully reflect lived experience of recovery (Stuart et al., 2017). Themes identified within trauma models of recovery are similar (e.g. Draucker et al., 2011), although again population-specific 
aspects remain present. For example, a qualitative study of the experiences of recovery by survivors of childhood sexual abuse described recovery as a unique, non-linear process involving recovery-enhancing factors such as meaningful activity and the strengthening of inner resources (Chouliara, et al., 2014). The model also emphasised aspects of recovery that are trauma-specific, such as the role of disclosure and shifting shame.

Sustained focus on personal recovery within mental health policy has put services under increasing pressure to evidence the extent to which their work is producing recovery-related outcomes (Williams et al., 2012). Routine Outcome Measures (ROMs) are widely used to provide evidence of such outcomes (McKay et al., 2014). ROMs can be used to capture service users' perspectives within the support process, providing useful data on the needs of people using services, service impact and change over time (Slade, 2002). Whilst use of ROMs is widely considered best practice, implementation challenges remain (Mellor-Clark et al., 2016). Many of the most commonly used ROMs have been criticised for not measuring personally meaningful outcomes, and for not capturing the service user's perspective (Happell, 2008). The challenge is therefore to create outcome measures which take a user perspective and assess outcomes that are both personally meaningful and useful at a service level (Miller et al., 2017). Such an opportunity is provided by the development of personal recovery measures (Slade, 2010). These instruments offer an approach to measurement that focuses on the person, their experiences and hopes for the future. Used as a key-working tool, individual-level recovery measures can play a meaningful role in support by promoting dialogue between service users and practitioners (Burgess et al., 2010). Whilst many recovery measures have been developed based on a mental health recovery model, none have yet been developed within a trauma setting.

Conceptual overlap between models of recovery proposed within the two fields suggests that tools developed within mental health may also be applied within a trauma population, but population-specific differences (Chouliara et al., 2014) highlight the need for further testing before these can be confidently applied in practice. Although personal recovery measures have been psychometrically examined within samples that include people with a diagnosis of PTSD (Pelletier et al., 2015), and alongside measures related to post-traumatic growth (Moran et al., 2012), no research has yet evaluated the validity of personal recovery measures exclusively within a population of people with experience of trauma. This paper therefore seeks to evaluate the psychometric properties of one such recovery measure, the Individual Recovery Outcomes Counter (I.ROC), in a trauma population. 
I.ROC is a brief personal recovery outcomes measure developed in Scotland by practitioners and people with lived experience of mental health issues (Monger et al., 2013). I.ROC is one of the few tools designed for use as a therapeutic instrument as well as an outcome measure. This can be argued to be fundamental to the meaningful application of routine outcome measures (ROMs) in practice. Accompanying staff training and guidance focuses on how questions can be used to guide conversation, whilst prompt words and illustrative graphics (figure 2) encourage in-depth exploration of each indicator. The measure is also situated within a 'wellbeing framework' called HOPE (Home, Opportunity, People and Empowerment), which provides an overarching structure for conceptualising recovery focused practice (figure 1). I.ROC was named in the Scottish Mental Health Strategy 2017-2027 as a tool to facilitate a "recovery-oriented and rights-based approach" (Scottish Government, 2017, p.35), and is used in a growing number of practice settings across health and social care services in the UK and internationally (Pincus et al., 2016), including trauma services in Scotland. Initial psychometric testing of the measure within samples of adults accessing community mental health services in Scotland support the reliability and validity of the measure (Dickens et al., 2017; Monger et al., 2013), however the psychometric properties of I.ROC have yet to be assessed within other populations, including the trauma population to which it has been applied in practice.

\section{Insert Figure 1}

\section{Insert Figure 2}

\section{.1. Aim}

The objective of this study was to extend previous research into I.ROC by evaluating preliminary evidence for the validity and reliability of the instrument within a trauma population. Internal consistency, structural and convergent validity with measures of self-esteem, anxiety and depression, and work and social adjustment were assessed.

\section{.2. Hypotheses}

Internal consistency was expected to be 'acceptable' (>.7) or higher (George \& Mallery, 2003), and measures were predicted to show 'moderate' (>.5) to 'good' (>.8) convergent validity (Cohen, 1988; Gaskin \& Happell, 2014) with I.ROC. Based on the scoring format of each questionnaire, negative correlations were predicted between I.ROC and measures of clinical symptoms and work and social adjustment; a positive correlation was expected with self-esteem. 
Finally, it was expected that the underlying structure of I.ROC would be similar to mental health populations (e.g. Monger et al, 2013; Dickens et al, 2017).

\section{Methods}

\section{Study Design}

This study was conducted as a secondary analysis of data from a wider study investigating therapeutic interventions for adult survivors of psychological trauma.

\section{Participants and procedure}

Participants $(n=107)$ were adult survivors of trauma, referred by general practitioners, psychiatrists, or psychologists for psychological therapy at a National Health Service trauma centre in Scotland. The Life Events Checklist (LEC-5; Grey et al., 2004) and Childhood Trauma Questionnaire (CTQ; Bernstein \& Fink, 1998) were used to assess history of traumatic life events; symptoms of PTSD were assessed using the International Trauma Questionnaire (Cloitre et al., 2018). Reasons for referral included both childhood and adulthood trauma or both, as well as single and multiple traumatic events. Types of traumas experienced range from childhood abuse and neglect to adulthood interpersonal traumas and accidents.

All participants were sent a covering letter, and invited to complete a set of standardised measures after providing informed consent. Participation was voluntary and anonymous. This study received ethical approval from Abertay University research ethics committee, and clinical governance approval from NHS Lothian.

\section{Measures}

Participants completed a questionnaire on demographics including gender, age, ethnicity, employment, marital and living arrangements, and the following self-report measures.

Individual Recovery Outcome Counter(I.ROC; Monger et al. 2013): I.ROC is a 12 -item measure of personal recovery, as described in Figure 1 (see Monger et al, 2013, for more detailed description of items). The tool aims to establish and subsequently track an individual's level of personal recovery across four domains (Hope, Opportunity, People, and Empowerment), each comprising three items describing an issue important in personal recovery (see Figure 1). Questions are asked on a 6-point frequency scale ranging from 1 'Never' to 6 'All the Time', with higher scores representing greater progress towards personal recovery. Prompt words and graphics accompany each question, as 
shown in Figure 2. In a sample of 171 adults accessing community mental health services in Scotland, I.ROC demonstrated good internal consistency and convergent validity with measures of recovery and clinical outcomes (Monger et al., 2013). Test-retest reliability of the measure is also good; ( $\mathrm{n}=70 ; \mathrm{r}=0.9, \mathrm{p}<0.001$; Dickens et al, 2017). There is little agreement on the factor structure of the measure reported; papers have reported adequate fit statistics for a uni-dimensional, two-factor, and four-factor solution (Dickens et al, 2017).

Rosenberg Self-Esteem Scale (RSES: Rosenberg, 1965): RSES consists of 10 Likert-type scale items designed to assess positive and negative evaluations of self. Respondents indicate their level of agreement ranging from 1 (strongly disagree) to 4 (strongly agree). Scores range from 10 to 40, with higher scores reflecting more positive evaluations of self. The RSES has demonstrated good psychometric properties among clinical samples (Schmitt \& Allik, 2005).

Hospital Anxiety and Depression Scale (HADS; Zigmond \& Snaith 1983): HADS is a 14 item self-report measure that assesses the presence and frequency of common mental illness symptoms using a four-point (0-3) scale. Scores are summed within two 7-item subscales measuring anxiety and depressive symptoms, with higher scores reflecting a greater presence and/or frequency of the symptom being addressed. The HADS has demonstrated good psychometric properties among clinical samples (Bjelland et al., 2002).

Work and Social Adjustment Scale (WSAS; Mundt et al., 2002): WSAS is a 5-item self-report scale that assesses perceived functional impairment in five domains; work, home management, social leisure activities, private leisure activities and relationships with others. Each domain is assessed using a single item with responses given on a scale ranging from 'Not at all' (0) to 'Very severely' (8). The WSAS has been found to provide reliable and valid scores and be a useful indicator of global dysfunction (Jansson-Fröjmark, 2014).

\section{Data Analysis}

As the percentage of missing data was small (maximum per item: 4.6\%); the expectation- maximization (EM) method was used to address missing data (Little \& Rubin, 2002). Data were analysed using the Statistical Package for Social Sciences (SPSS) version 23 and AMOS v22. Means (SDs) were calculated for continuous variables and frequencies (\%) for categorical variables (table 5). Summed total scores fell within the range assumed for normal distribution (George \& Mallery, 2003); convergent validity was therefore calculated using Pearson's r; effect sizes are reported alongside 95\% confidence intervals (CI); the critical level of significance was set at 5\%. Reliability analysis used Cronbach's alpha. 
A two-stage analysis of I.ROC's latent structure was conducted. Confirmatory Factor Analysis (CFA) was used to evaluate the goodness of fit of previously proposed structural models: the four-factor HOPE framework (Dickens et al., 2017), two-factor models separating recovery into inter and intrapersonal dimensions (Dickens et al., 2017; Monger et al., 2013), and a unidimensional model (Dickens et al., 2017). Goodness of fit for each model was examined using 1) chi-squared statistic (CMIN), 2) comparative fit index (CFI), the incremental fit index (IFI), 3) standardised root-meansquare residual (SRMR) and the root mean square error of approximation (RMSEA). A non-significant model chisquare and values greater than .95 for CFI and IFI are considered good model fit (Hu \& Bentler, 1999). A $\chi 2 / \mathrm{df}$ ratio less than 3 indicates good fit (Byrne, 2001). Values of the SRMR below .08 and of the RMSEA below .05 show excellent fit although values between .05 and .08 indicate acceptable fit (Hu \& Bentler, 1999).

Secondly, the latent structure of I.ROC was explored using Principal Component Analysis (PCA) with oblique direct oblimin rotation. Factor loadings below .3 were suppressed, and items loading on more than one factor were assigned to the factor with the highest factor loading.

\section{Results}

\section{Demographics}

Participants $(n=107,92.5 \%$ female) ranged in age from 18 to 78 years $(M=38.8 \mathrm{SD}=10.8)$ were primarily Scottish $(\mathrm{N}=79,73.8 \%)$ and single $(\mathrm{n}=61,57.0 \%)$. Approximately one-third of the participants were living alone $(35.5 \%)$ and two-thirds were living with others (e.g. a partner or with family; 64.5\%). Over half of the cohort attended further or higher education $(n=63,58.9 \%)$. Socio-demographic characteristics of the sample are summarised in Table 1.

\section{Insert Table 1}

\section{Descriptive Statistics}

Exploratory data analysis was conducted to test the normality of data. Results from the Shapiro-Wilk's test and Kolmogorov-Smirnov's test along with visual inspection of histograms showed that the data were normally distributed. I.ROC scores ranged from 14 to 52 (max possible range: $12-72)$, with a mean of $33.3(\mathrm{SD}=7.8)$. Item means were fairly low, ranging from 2.08 for 'Social Network', to 3.34 for 'Participation \& Control', and several items saw substantial floor effects (see Table 2). 
Internal consistency for total scores of each measure was acceptable to good, ranging from .73 (RSES) to .82 (HADS), as reported alongside means (SD) and correlation coefficients in Table 5. Inter-item correlations for I.ROC were fairly low however, with only 15 of the 66 inter-item correlations exceeding the acceptability limit of .3 (Cohen, 1988).

\section{Insert Table 2}

\section{Confirmatory Factor Analysis}

Results of confirmatory factor analysis testing are presented in Table 3. Of the four models proposed in previous publications (Dickens et al., 2017; Monger et al., 2013), the two-factor model identified by Dickens and colleagues (model 3) produced the best fit, however no model met acceptable limits for a good fit. Although the $\chi^{2} / \mathrm{df}$ ratio was within the accepted range for all models and SRMR was acceptable with the exception of model 1 (SRMR=.09), CFI and IFI statistics fell outside the acceptable range (<.8) in all cases. RMSEA values were only just acceptable (.08) for the unidimensional and 2-factor solutions offered by Dickens et al (2017), and were outside the accepted range for all other models. Chi square statistics were highly significant $(\mathrm{p}<.001)$ in all cases. A new analysis using exploratory methods was therefore conducted.

\section{Insert Table 3}

\section{Principal Components Analysis}

The 12 I.ROC items were subjected to principal components analysis (PCA) using SPSS v22. Prior to performing PCA, the suitability of data for factor analysis was assessed. Inspection of the correlation matrix revealed the presence of many coefficients of .3 and above. The KMO value was .77 exceeding the recommended value of .6 (Kaiser 1974) and the Bartlett's test of sphericity $\left(\chi^{2}=310.56, p<.001\right)$ reached statistical significance, supporting the factorability of the correlation matrix. An initial PCA with direct oblimin rotation revealed the presence of four components with eigenvalues exceeding 1 , (eigenvalues $3.5,1.4,1.2$, and 1.1) accounting for $62.14 \%$ of the variance, however the factor structure was problematic. Four items loaded strongly on factor one and three items loaded strongly on factor four, but two items (Personal Network; Life Skills) showed significant cross-loadings. These items were assigned to the factor with the highest loading. Factor three comprised two items, but these items loaded on the factor in opposite directions (Social Network .768; Life Skills -.506). Personal network loaded strongly with two negative items (Purpose \& 
Direction, Exercise \& Activity) in Factor 3. The correlation matrix revealed there were non-significant correlations between SN and six items (Mental Health, Life Skills, Safety \& Comfort, Personal Network, Valuing Myself, and Self Management). Similarly, there were non-significant associations between Personal Network and six items (Life Skills, Physical Health, Exercise \& Activity, Purpose \& Direction, Social Network, and Valuing Myself). Further analysis was performed to check whether the internal consistency of the scale would increase with the exclusion of Social Network first followed by the exclusion of Social Network and Personal Network items. For the 11-item scale (Social Network excluded), the Cronbach's $\alpha$ was .76 (the same findings as the 12-item scale) and a 10-item scale (Social Network and Personal Network excluded) revealed an increase of internal consistency $(\alpha=.77)$.

A further PCA with direct oblimin rotation was therefore conducted excluding the two problematic items (Social Network and Personal Network). This generated three components with eigenvalues exceeding 1 (3.61, 1.23 and 1.07), accounting for $59.1 \%$ of the variance. As shown in Table 4, all 10 items loaded strongly on three components (item loadings ranging from .62 to .85) with four items loading on component 1, four items on component 2 and two items on component 3 (see Table 4). There was no cross loading of factor items following rotation. Internal consistency was 'good' for the first component, but low for two and three (Cronbach's $\alpha$ values: .77, .62, .53). Pearson's correlation between the original 12 items I.ROC and the reduced 10-item version showed good concurrent validity $(\mathrm{r}=.97, \mathrm{p}<.01)$.

\section{Insert Table 4}

\section{Convergent validity}

Total scores of all four measures correlated significantly in the predicted directions, as reported in Table 5. I.ROC correlated positively with self-esteem $(\mathrm{r}=.51, \mathrm{p}<.001,95 \% \mathrm{CI}[.35, .65])$, and negatively with anxiety and depression (HADS total: $\mathrm{r}=-.61, \mathrm{p}<.001,95 \% \mathrm{CI}[-.65,-.35])$, such that people with fewer self-identified symptoms of depression and anxiety had higher levels of recovery, whilst those with higher self-esteem reported greater personal recovery. Scores on the Work and Social Adjustment Scale were likewise inversely correlated to I.ROC (r=-.39, p<.001, 95\% CI $[-.56,-.19])$; although the effect size was smaller, people showing greater levels of impairment in work and social adjustment scored higher on I.ROC. 
As shown in Table 5, I.ROC components identified using PCA correlated significantly with total and subscale scores for these three measures, with the exception of the relationship between Component 3 (Meaningful Activity) and the Anxiety subscale of HADS ( $\mathrm{r}=.15, \mathrm{p}=.06,95 \% \mathrm{CI}[-.04,-.33])$.

\section{Insert Table 5}

\section{Discussion}

The primary aim of this paper was to evaluate for the first time the validity and reliability of a self - report version of the recovery outcome measure I.ROC (Monger et al., 2013) in a sample of adults accessing trauma-related services in Scotland. Participants completed a battery of outcome measures, and results were used to assess the internal consistency, convergent and structural validity of I.ROC. Results support the validity and reliability of I.ROC as a selfreport recovery measure for use by trauma survivors.

Confirmatory factor analysis showed that four previously proposed models (Dickens et al., 2017; Monger et al., 2013) did not produce a good fit. Subsequent exploratory analysis suggested an alternative three-factor structure explaining 59\% of the variance. The three components within the retained model were labelled as Psychological Wellbeing \& Health; Decision-making \& Life Skills; and Meaningful Activity.

The model excluded two items, Personal Network and Social Network, suggesting further revisions to I.ROC may be necessary. These items are not yet recommended for removal from the questionnaire however, for several reasons. Brevity was a key issue for I.ROC developers, and consequently each question was designed to measure a different aspect of recovery. Personal and social connections together are commonly identified as one of several key elements of personal recovery (Leamy et al., 2011). Positive supportive relationships are equally central to models of recovery following trauma (Herman, 2015); Personal and Social Network are the only items within I.ROC exploring this fundamental recovery component. Lloyd and colleagues propose a multi-dimensional model of recovery, in which social and personal recovery are conceived as distinct dimensions alongside clinical and functional recovery (Lloyd, Waghorn \& Williams, 2008), and it may be that such a conceptualisation aligns more closely with the experiences of trauma survivors. Fitzpatrick and colleagues point out that excessive reliance on exploratory factor analysis can result in situations where experiences of importance to respondents are found to be statistically unrelated and therefore omitted from a measure (Fitzpatrick et al., 1998). Nevertheless, poor fit of items measuring social aspects of recovery is a 
concern, which merits further exploration. Furthermore, several I.ROC items, including Social Network, showed substantial floor effects. This suggests, as has been previously recommended (Dickens et al, 2017), that the scale may need further revisions in order to reflect the full recovery continuum. I.ROC was designed to be used not only as a measure, but as a therapeutic instrument, promoting recovery-related conversation and exploration of key areas of importance to service users. It is therefore important that revisions to the items within I.ROC are reflective of service user's perspectives on what is important to their recovery, as well as what items produce the best statistical fit.

\section{$\underline{\text { Limitations }}$}

Principal Components Analysis is a data reduction methodology, with the goal of reducing the data set into the minimum number of components, and this may produce, in some cases, artificial results (Preacher \& MacCallum, 2003). It has also been argued that it actually produces structures that are similar to EFA methods (Henson \& Roberts, 2006).

With only 107 participants, the sample size used within this study can be considered relatively small. Psychometric analyses require large samples to maximise power, and in the case of factor analysis in particular, sample sizes far exceeding 100 are strongly recommended (Gaskin \& Happell, 2014). Reflecting the demographics of trauma survivors accessing the service during the study period, the sample comprised a large female majority (92.5\%). Genderrelated differences are well documented within trauma and mental health research. Males and females vary in terms of their exposure to different types of trauma (Benjet et al., 2016); prevalence rates of diagnosed trauma-related stress disorders (e.g. PTSD) are substantially higher in women (Tolin \& Foa, 2016), as is help-seeking and mental health service use (Wendt \& Shafer, 2016). Nevertheless, the proportion of women in this study may be considered too high to be fully representative. Research with a larger and more gender-balanced dataset is therefore recommended to further explore the structural validity of I.ROC in a trauma population.

Significant correlations with measures of self-esteem, work and social adjustment and common mental health issues provide support for the convergent validity of I.ROC. It is interesting to note that the strongest correlation was found between I.ROC and HADS, a measure of symptoms of mental illness. Similarly strong correlations with measures of clinical symptoms have been reported in psychometric evaluations of several recovery measures (e.g. 
Drapalski et al., 2016). This supports the argument presented within a growing body of research (Resnick et al., 2004) that personal and clinical recovery are related, not necessarily opposing, concepts.

Finally, this study was conducted as a post-hoc secondary analysis of data from a wider study investigating therapeutic interventions for adult survivors of psychological trauma. Whilst convergent validity was assessed against a range of measures associated with the recovery construct, analysis did not include any directly comparative validated measures of personal recovery. It is acknowledged that inclusion of such an instrument would have enabled a fuller evaluation of convergent validity. Future research into the validity of I.ROC should seek to include a more direct benchmark.

\section{Conclusion}

This study extends previous research into the validity and applicability of personal recovery measures by evaluating the psychometric properties of one such measure, I.ROC, within a new population of adults accessing trauma-related support. Structural validity testing showed some variation to previous research in mental health populations; principal components analysis suggested a three-factor structure with acceptable internal consistency, comprising ten of the original twelve items (I.ROC-10). As hypothesised, correlations with measures of self-esteem, mental illness symptoms and functional impairment reached significance for the original and modified I.ROC and its subscales, supporting the convergent validity of the instrument.

These results provide initial support for the validity and reliability of I.ROC as a measure of self-reported recovery for people with trauma-related diagnoses. More research is needed in larger, more diverse samples and with a broader range of instruments, to confirm these findings and to further evaluate the structure of this measure. As I.ROC is designed to be used on a regular basis to map change over time, future studies should also seek to assess sensitivity to change.

\section{Relevance for clinical practice}

As mental health services continue to come under increasing pressure to evidence the extent to which their work is recovery-oriented (Williams et al., 2012), personal recovery measures provide an effective means of evaluating recovery orientation. Such measures assess outcomes that are both personally meaningful and useful at a service level, fundamental properties of any routine outcomes measure (Happell, 2008). Clinically, measures can be used within support to reflect on the recovery journey and identify recovery outcomes to work towards, as well as to measure 
progress (Burgess et al., 2010). Findings of this study suggest that use of such recovery measures, in particular I.ROC, in addition to their use within the general mental health sector, can be successfully used with trauma survivors. 


\section{References}

Bassuk, E.L., Latta, R.E., Sember, R., Raja, S. and Richard, M., 2017. Universal Design for Underserved Populations: Person-Centered, Recovery-Oriented and Trauma Informed. Journal of health care for the poor and underserved, 28(3), pp.896-914.

Benjet, C., Bromet, E., Karam, E.G., Kessler, R.C., McLaughlin, K.A., Ruscio, A.M., Shahly, V., Stein, D.J., Petukhova, M., Hill, E. and Alonso, J., 2016. The epidemiology of traumatic event exposure worldwide: results from the World Mental Health Survey Consortium. Psychological medicine, 46(2), pp.327-343.

Bernstein, D.P. and Fink, L., 1998. Childhood trauma questionnaire: A retrospective self-report: Manual. Harcourt Brace \& Company.

Bjelland, I., Dahl, A. A., Haug, T. T., \& Neckelmann, D. (2002). The validity of the hospital anxiety and depression scale: An updated literature review. Journal of Psychosomatic Research, 52(2), 69-77. doi:10.1016/S00223999(01)00296-3

Burgess, P., Pirkis, J., Coombs, T., \& Rosen, A. (2010). Review of recovery measures. Australian Mental Health Outcomes and Classification Network, 1, 1-78.

Byrne, B. M. (2001). Structural equation modeling with AMOS: Basic concepts, applications, and programming (1st ed.) Routledge.

Chouliara, Z., Karatzias, T., \& Gullone, A. (2014). Recovering from childhood sexual abuse: A theoretical framework for practice and research. Journal of Psychiatric and Mental Health Nursing, 21(1), 69-78. doi:10.1111/jpm.12048

Chouliara, Zoe, Karatzias, Thanos, Scott-Brien, Georgia, Macdonald, Anne, MacArthur, Juliet, \& Frazer, Norman. (2011). Talking Therapy Services for Adult Survivors of Childhood Sexual Abuse (CSA) in Scotland: Perspectives of Service Users and Professionals. Journal of Child Sexual Abuse, 20(2), 128-156.

Cloitre, M., Shevlin, M., Brewin, C.R., Bisson, J.I., Roberts, N.P., Maercker, A., Karatzias, T. and Hyland, P., 2018. The International Trauma Questionnaire: development of a self-report measure of ICD-11 PTSD and complex PTSD. Acta Psychiatrica Scandinavica, 138(6), pp.536-546.

Cohen, J. (1988). Statistical power analysis for the behavioral sciences. Hilsdale. NJ: Lawrence Earlbaum Associates, 2

Dickens, G. L., Rudd, B., Hallett, N., Ion, R. M., \& Hardie, S. M. (2017). Factor validation and rasch analysis of the individual recovery outcomes counter. Disability and Rehabilitation, , 1-12.

Drapalski, A. L., Medoff, D., Dixon, L., \& Bellack, A. (2016). The reliability and validity of the maryland assessment of recovery in serious mental illness scale. Psychiatry Research, 239, 259-264. doi:10.1016/j.psychres.2016.03.031

Draucker, Claire Burke, Martsolf, Donna S., Roller, Cynthia, Knapik, Gregory, Ross, Ratchneewan, \& Stidham, Andrea Warner. (2011). Healing from Childhood Sexual Abuse: A Theoretical Model. Journal of Child Sexual Abuse, 20(4), 435-466.

Fitzpatrick, R., Davey, C., Buxton, M. J., \& Jones, D. R. (1998). Evaluating patient based outcome measures for use in clinical trials. Health Technology Assessment, 2(14) 
Gaskin, C., \& Happell, B. (2014). Power, effects, confidence, and significance: An investigation of statistical practices in nursing research. International Journal of Nursing Studies, 51(5), 795-806.

doi:10.1016/j.ijnurstu.2013.09.014

George, D., \& Mallery, P. (2003). SPSS for windows step by step: A simple guide and reference. 11.0 update (4th ed.). Boston: Allyn \& Bacon.

Gray, M.J., Litz, B.T., Hsu, J.L. and Lombardo, T.W., 2004. Psychometric properties of the life events checklist. Assessment, 11(4), pp.330-341.

Happell, B. (2008). The value of routine outcome measurement for consumers of mental health services: Master or servant? The International Journal of Social Psychiatry, 54(4), 317.

Henson, R. K., \& Roberts, J. K. (2006). Use of exploratory factor analysis in published research: Common errors and some comment on improved practice. Educational and Psychological Measurement, 66(3), 393-416. doi:10.1177/0013164405282485

Herman, J. L. (2015). Trauma and recovery: The aftermath of violence--from domestic abuse to political terror Hachette UK.

Hu, L., \& Bentler, P. M. (1999). Cutoff criteria for fit indexes in covariance structure analysis: Conventional criteria versus new alternatives. Structural Equation Modeling: A Multidisciplinary Journal, 6(1), 1-55.

Jansson-Fröjmark, M. (2014). The work and social adjustment scale as a measure of dysfunction in chronic insomnia: Reliability and validity. Behavioural and Cognitive Psychotherapy, 42(2), 186-198.

Leamy, M., Bird, V., Le Boutillier, C., Williams, J., \& Slade, M. (2011). Conceptual framework for personal recovery in mental health: Systematic review and narrative synthesis. British Journal of Psychiatry, 199(6), 445452. doi:10.1192/bjp.bp.110.083733

Lewis, S.J., Arseneault, L., Caspi, A., Fisher, H.L., Matthews, T., Moffitt, T.E., Odgers, C.L., Stahl, D., Teng, J.Y. and Danese, A., 2019. The epidemiology of trauma and post-traumatic stress disorder in a representative cohort of young people in England and Wales. The Lancet Psychiatry, 6(3), pp.247-256.

Little, R. J., \& Rubin, D. B. (2002). Bayes and multiple imputation. Statistical Analysis with Missing Data, Second Edition, , 200-220.

Lloyd, C., Waghorn, G., \& Williams, P. L. (2008). Conceptualising recovery in mental health rehabilitation. The British Journal of Occupational Therapy, 71(8), 321-328. doi:10.1177/030802260807100804

McChesney, G.C., Adamson, G. and Shevlin, M., 2015. Service use patterns and mental health symptoms among adolescents exposed to multiple types of trauma. Journal of adolescence, 40, pp.1-10.

Mckay, R., Coombs, T., \& Duerden, D. (2014). The art and science of using routine outcome measurement in mental health benchmarking. Australasian Psychiatry, 22(1), 13-18.

Mellor-Clark, J., Cross, S., Macdonald, J., \& Skjulsvik, T. (2016). Leading Horses to Water: Lessons from a Decade of Helping Psychological Therapy Services Use Routine Outcome Measurement to Improve Practice.

Administration and Policy in Mental Health and Mental Health Services Research, 43(3), 279-285.

Miller, E., Stanhope, V., Restrepo-Toro, M., \& Tondora, J. (2017). Person-centered planning in mental health: A transatlantic collaboration to tackle implementation barriers. American Journal of Psychiatric Rehabilitation, 20(3), 251-267. 
Mills, K.L., McFarlane, A.C., Slade, T., Creamer, M., Silove, D., Teesson, M. and Bryant, R., 2011. Assessing the prevalence of trauma exposure in epidemiological surveys. Australian \& New Zealand Journal of Psychiatry, 45(5), pp.407-415.

Monger, B., Hardie, S., Ion, R., Cumming, J., \& Henderson, N. (2013). The individual recovery outcomes counter: Preliminary validation of a personal recovery measure. The Psychiatrist, 37(7), 221.

Moran, G. S., Russinova, Z., \& Stepas, K. (2012). Toward understanding the impact of occupational characteristics on the recovery and growth processes of peer providers. Psychiatric Rehabilitation Journal, 35(5), 376-380. doi:10.1037/h0094496

Mueser, K. T., Goodman, L. B., Trumbetta, S. L., Rosenberg, S. D., Osher, F. C., Vidaver, R., Foy, D. W. (1998). Trauma and posttraumatic stress disorder in severe mental illness. Journal of Consulting and Clinical Psychology, 66(3), 493.

Mundt, J., Marks, I., Shear, M., \& Greist, J. (2002). The work and social adjustment scale: A simple measure of impairment in functioning. British Journal of Psychiatry, 180, 461-464.

Muskett, Coral. Trauma-informed Care in Inpatient Mental Health Settings: A Review of the Literature. International Journal of Mental Health Nursing 23.1 (2014): 51-59. Web.

Pelletier, J., Corbiere, M., Lecomte, T., Briand, C., Corrigan, P., Davidson, L., \& Rowe, M. (2015). Citizenship and recovery: Two intertwined concepts for civic-recovery. Bmc Psychiatry, 15, 37. doi:10.1186/s12888-015-0420-2

Perkins, R., \& Repper, J. (2015). Recovery is possible for everyone? Mental Health and Social Inclusion, 19(2)

Pincus, H. A., Spaeth-Rublee, B., Sara, G., Goldner, E. M., Prince, P. N., Ramanuj, P., . . Patton, L. (2016). A review of mental health recovery programs in selected industrialized countries. International Journal of Mental Health Systems, 10 doi:10.1186/s13033-016-0104-4

Preacher, K. J., \& MacCallum, R. C. (2003). Repairing tom swift's electric factor analysis machine. Understanding Statistics, 2(1), 13-43. doi:10.1207/S15328031US0201_02

Resnick, S. G., Rosenheck, R. A., \& Lehman, A. F. (2004). An exploratory analysis of correlates of recovery. Psychiatric Services, 55(5), 540-547.

Schmitt, D. P., \& Allik, J. (2005). Simultaneous administration of the rosenberg self- esteem scale in 53 nations: Exploring the universal and culture- specific features of global self- esteem. Journal of Personality and Social Psychology, 89(4), 623-642. doi:10.1037/0022-3514.89.4.623

Scottish Government, S. (2017). Mental health strategy for scotland: 2017-2027. Edinburgh: Scottish Government.

Slade, M. (2002). What outcomes to measure in routine mental health services, and how to assess them: A systematic review. Australian \& New Zealand Journal of Psychiatry, 36(6), 743-753.

Slade, M. (2010). Measuring recovery in mental health services. The Israel Journal of Psychiatry and Related Sciences, 47(3), 206-212.

Stuart, S.R., Tansey, L. and Quayle, E., 2017. What we talk about when we talk about recovery: a systematic review and best-fit framework synthesis of qualitative literature. Journal of Mental Health, 26(3), pp.291-304

Substance Abuse and Mental Health Services Administration (2014) SAMHSA's Concept of Trauma and Guidance for a Trauma-Informed Approach (HHS Publication No. (SMA) 14-4884). SAMHSA 
Tolin and Foa, 2006. Tolin D.F., and Foa E.B.: Sex differences in trauma and posttraumatic stress disorder: A quantitative review of 25 years of research. Psychological Bulletin 2006; 132: pp. 959-992

Van Weeghel, J., Van Zelst, C., Boertien, D., \& Hasson-Ohayon, I. (2019). Conceptualizations, assessments, and implications of personal recovery in mental illness: A scoping review of systematic reviews and meta-analyses. Psychiatric Rehabilitation Journal, doi:10.1037/prj0000356

Wendt, Douglas, and Kevin Shafer. "Gender and Attitudes about Mental Health Help Seeking: Results from National Data." Health \& Social Work 41.1 (2016)

Williams, J., Leamy, M., Bird, V., Harding, C., Larsen, J., Le Boutillier, C., . . Slade, M. (2012). Measures of the recovery orientation of mental health services: Systematic review. Social Psychiatry and Psychiatric Epidemiology, 47(11), 1827-1835. doi:10.1007/s00127-012-0484-y

Zigmond, A. S., \& Snaith, R. P. (1983). The hospital anxiety and depression scale. Acta Psychiatrica Scandinavica, 67(6), 361-370. 


\section{List of Tables}

Table 1: Sample Demographic Information $(n=107)$

Table 2: Descriptive statistics for the 12 I.ROC items

Table 3: CFA Fit Indices for the previously published models

Table 4: Factor loadings, correlations and internal consistency for the final rotated solution

Table 5: Means, standard deviation, internal consistency and correlations between all continuous variables

\section{List of Figures}

Figure 1: I.ROC items cover the following domains: mental health, life skills, safety \& comfort, physical health, exercise $\&$ activity, purpose $\&$ direction, personal network, social network, valuing myself, participation \& control, self-management, hope for the future (see Monger et al., 2013 for more detailed description of indicators). Here, the twelve I.ROC items are shown situated within the four areas of the HOPE framework. In the middle of the image, baseline and review scores for one person are shown on a radar graph.

Figure 2: Example page from the I.ROC questionnaire showing the Mental Health item. This demonstrates the format for each of twelve questions, which includes colourful graphics and a list of prompt words

Copyright for both images is held by Penumbra; permission for image reproduction has been granted by Nigel Henderson, Chief Executive of Penumbra. 


\section{List of Tables}

Table 1: Sample Demographic Information $(n=107)$

Table 2: Descriptive statistics for the 12 I.ROC items

Table 3: CFA Fit Indices for the previously published models

Table 4: Factor loadings, correlations and internal consistency for the final rotated solution

Table 5: Means, standard deviation, internal consistency and correlations between all continuous variables 
Table 1. Sample Demographic Information $(n=107)$ and I.ROC univariate statistics

\begin{tabular}{|c|c|}
\hline & $\mathrm{M}(S D)$ \\
\hline Age $(F=1.7, p=.2)$ & $\begin{array}{c}38.9(10.8) \\
\%\end{array}$ \\
\hline \multicolumn{2}{|l|}{ Gender $(t=-.39, p=.7)$} \\
\hline Female & 92.5 \\
\hline Male & 7.5 \\
\hline \multicolumn{2}{|l|}{ Ethnicity $(F=1.16, p=.3)$} \\
\hline British & 86.7 \\
\hline Irish & 0.9 \\
\hline Other (e.g. Other European, Indian etc.) & 8.0 \\
\hline No Response & 4.4 \\
\hline \multicolumn{2}{|l|}{ Education $(t=-.74, p=.5)$} \\
\hline Basic Education & 68.2 \\
\hline Higher Education & 31.8 \\
\hline \multicolumn{2}{|l|}{ Employment $(F=1.34, p=.3)$} \\
\hline Full time & 17.1 \\
\hline Part time & 13.3 \\
\hline Unemployed & 67.6 \\
\hline Retired & 2.0 \\
\hline \multicolumn{2}{|l|}{ Marital Status $(F=.17, p=.9)$} \\
\hline Single & 58.7 \\
\hline Married/civil-partnership & 9.6 \\
\hline Co-habiting & 10.6 \\
\hline Divorced/separated & 15.4 \\
\hline Other (e.g.) & 5.7 \\
\hline \multicolumn{2}{|l|}{ Living Arrangements $(F=.29, p=.8)$} \\
\hline Living alone & 35.5 \\
\hline Living with partner & 17.8 \\
\hline $\begin{array}{l}\text { Living with family members and/or others (e.g. flat } \\
\text { sharing) }\end{array}$ & 46.7 \\
\hline
\end{tabular}


Table 2: Descriptive statistics for the 12 I.ROC items

\begin{tabular}{|c|c|c|c|c|}
\hline & Mean Score & \% Scoring 1 & $\%$ Scoring 6 & $\begin{array}{c}\text { Inter-item } \\
\text { correlations } \\
<.3\end{array}$ \\
\hline Mental Health & 2.18 & 25.5 & 0 & 5 \\
\hline Life Skills & 3.14 & 11.3 & 4.7 & 9 \\
\hline Safety \& Comfort & 3.32 & 7.7 & 6.7 & 11 \\
\hline Physical Health & 2.42 & 23.8 & 1 & 8 \\
\hline $\begin{array}{c}\text { Exercise \& } \\
\text { Activity }\end{array}$ & 2.91 & 27.1 & 5.6 & 9 \\
\hline $\begin{array}{c}\text { Purpose \& } \\
\text { Direction }\end{array}$ & 3.05 & 14 & 6.5 & 10 \\
\hline Personal Network & 3.14 & 14.2 & 10.4 & 9 \\
\hline Social Network & 2.08 & 43.9 & 1.9 & 11 \\
\hline Valuing Myself & 2.26 & 30.2 & 0 & 6 \\
\hline $\begin{array}{c}\text { Participation \& } \\
\text { Control }\end{array}$ & 3.34 & 10.4 & 7.5 & 10 \\
\hline Self Management & 2.88 & 7.5 & 0 & 7 \\
\hline $\begin{array}{c}\text { Hope for the } \\
\text { Future }\end{array}$ & 2.63 & 17 & 0 & 7 \\
\hline
\end{tabular}


Table 3: CFA Fit Indices for the previously published models

\begin{tabular}{clcccccccc}
\hline Model & Factor names (number of items loading) & CMIN & DF & CMIN/DF & $\boldsymbol{p}$ & CFI & IFI & SRMR & RMSEA [90\% CI ] \\
\hline $\mathbf{1}$ & Home (3); Opportunity (3); People (3); & 90.93 & 48 & 1.89 & .000 & 0.84 & 0.85 & 0.09 & $0.09[.062, .120]$ \\
$\mathbf{2}$ & $\begin{array}{l}\text { Empowerment (3) (Dickens et al, 2017) } \\
\text { Interpersonal (4); Intrapersonal (8) }\end{array}$ & 95.38 & 53 & 1.80 & .000 & 0.84 & 0.84 & 0.08 & $0.09[.058, .115]$ \\
$\mathbf{3}$ & $\begin{array}{l}\text { (Monger et al, 2013) } \\
\text { Interpersonal (4); Intrapersonal (8) }\end{array}$ & 91.54 & 53 & 1.73 & .001 & 0.85 & 0.86 & 0.08 & $0.08[.053, .111]$ \\
$\mathbf{4}$ & $\begin{array}{l}\text { (Dickens et al, 2017) } \\
\text { Unidimensional (12) (Dickens et al, 2017) }\end{array}$ & 96.84 & 54 & 1.79 & .000 & 0.84 & 0.85 & 0.08 & $0.08[.058, .114]$ \\
\hline
\end{tabular}


Table 4: Factor loadings, correlations and internal consistency for the final rotated solution

\begin{tabular}{|c|c|c|c|c|}
\hline & & C_1 & C_2 & C_3 \\
\hline Factor & & General wellbeing & Daily Living & $\begin{array}{c}\text { Meaningful } \\
\text { Activity }\end{array}$ \\
\hline \multicolumn{5}{|l|}{ Variables } \\
\hline Physical health & & .810 & & \\
\hline Hope for the Future & & .780 & & \\
\hline Valuing yourself & & .653 & & \\
\hline Mental Health & & .642 & & \\
\hline Participation \& Control & & & .698 & \\
\hline Safety \& Comfort & & & .687 & \\
\hline Self-Management & & & .631 & \\
\hline Life skills & & & .623 & \\
\hline Exercise \& Activity & & & & .850 \\
\hline Purpose \& Direction & & & & .724 \\
\hline$\alpha$ & & .77 & .62 & .53 \\
\hline \multirow{3}{*}{$\begin{array}{l}\text { Component } \\
\text { correlations }\end{array}$} & C 1 & - & & \\
\hline & $\mathrm{C} 2$ & .302 & - & \\
\hline & C 3 & .277 & .211 & - \\
\hline
\end{tabular}

Analysis based on extracted factors with Eigenvalues $>1$ (PCA Oblimin rotation with Kaiser Normalisation) 
Table 5: Means, standard deviation, internal consistency and correlations between all continuous variables

\begin{tabular}{|c|c|c|c|c|c|c|c|c|c|c|c|}
\hline & $\begin{array}{c}\text { Means } \\
(S D)\end{array}$ & $\alpha$ & $\begin{array}{c}\text { I.ROC } \\
(12)\end{array}$ & Anxiety & Depression & HADS & WSAS & RSES & I.ROC_C1 & I.ROC_C2 & I.ROC_C3 \\
\hline I.ROC (12 items) & $33.2(7.8)$ & .76 & - & & & & & & & & \\
\hline Anxiety & $15.5(3.6)$ & .77 & $-.407 * *$ & - & & & & & & & \\
\hline Depression & $11.8(4.4)$ & .78 & $-.647 * *$ & $.382 * *$ & - & & & & & & \\
\hline HADS & $27.3(6.6)$ & .82 & $-.647 * *$ & $.792 * *$ & $.867 * *$ & - & & & & & \\
\hline WSAS & $28.8(7.5)$ & .68 & $-.514 * *$ & $.255^{* *}$ & $.556 * *$ & $.505^{* *}$ & - & & & & \\
\hline RSES & $8.9(4.4)$ & .81 & $.572 * *$ & $-.330 * *$ & $-.499 * *$ & $-.508 * *$ & $-.289 * *$ & - & & & \\
\hline I.ROC_C1 & $9.3(3.1)$ & .77 & $.804 * *$ & $-.374 * *$ & $-.604 * *$ & $-.601 * *$ & $-.313 * *$ & $.584 * *$ & - & & \\
\hline I.ROC_C2 & $12.7(3.5)$ & .62 & $.767 * *$ & $-.408 * *$ & $-.419 * *$ & $-.496 * *$ & $-.484 * *$ & $.416^{* *}$ & $.440 * *$ & - & \\
\hline I.ROC_C3 & $5.9(2.5)$ & .55 & $.632 * *$ & -.150 & $-.484 * *$ & $-.401 * *$ & $-.278 * *$ & $.349^{* *}$ & $.396^{* *}$ & $.274 * *$ & - \\
\hline I.ROC-10 & $27.9(6.9)$ & .77 & $.969 * *$ & $-.425 * *$ & $-.652 * *$ & $-.660 * *$ & $-.482 * *$ & $.593 * *$ & $.809 * *$ & $.796^{* *}$ & $.672 * *$ \\
\hline
\end{tabular}

Note: I.ROC: Individual Recovery Outcomes Counter, I.ROC_C1: Personal Wellbeing \& Hope, I.ROC_C2: Decision-making \& Life Skills, I.ROC_C3: Meaningful Activity, HADS: Hospital Anxiety and Depression Scale, WSAS: Work and Social Adjustment Scale, RSES: Rosenberg self-esteem scale, PW\&H: Psychological wellbeing \& health, DM\& LS: Decision- making \& life skills, E\&MA: Employment \& Meaningful Activity, ** p<.001,* p<0.05 


\section{List of Figures}

Figure 1: I.ROC items cover the following domains: mental health, life skills, safety \& comfort, physical health, exercise \& activity, purpose \& direction, personal network, social network, valuing myself, participation \& control, self-management, hope for the future (see Monger et al., 2013 for more detailed description of indicators). Here, the twelve I.ROC items are shown situated within the four areas of the HOPE framework. In the middle of the image, baseline and review scores for one person are shown on a radar graph.

Figure 2: Example page from the I.ROC questionnaire showing the Mental Health item. This demonstrates the format for each of twelve questions, which includes colourful graphics and a list of prompt words

Copyright for both images is held by Penumbra; permission for image reproduction has been granted by Nigel Henderson, Chief Executive of Penumbra.

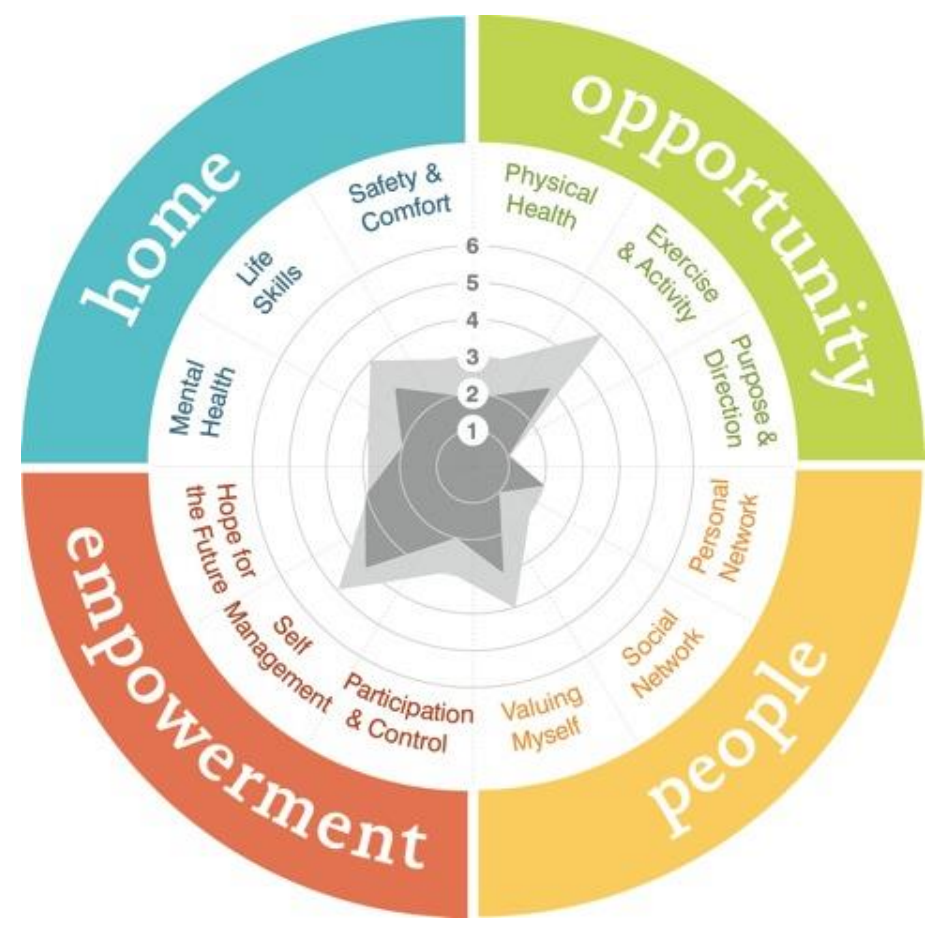

Figure 1: I.ROC items cover the following domains: mental health, life skills, safety \& comfort, physical health, exercise \& activity, purpose \& direction, personal network, social network, valuing myself, participation \& control, self-management, hope for the future (see Monger et al., 2013 for more detailed description of indicators). Here, the twelve I.ROC items are shown situated within the four areas of the HOPE framework. In the middle of the image, baseline and review scores for one person are shown on a radar graph. 


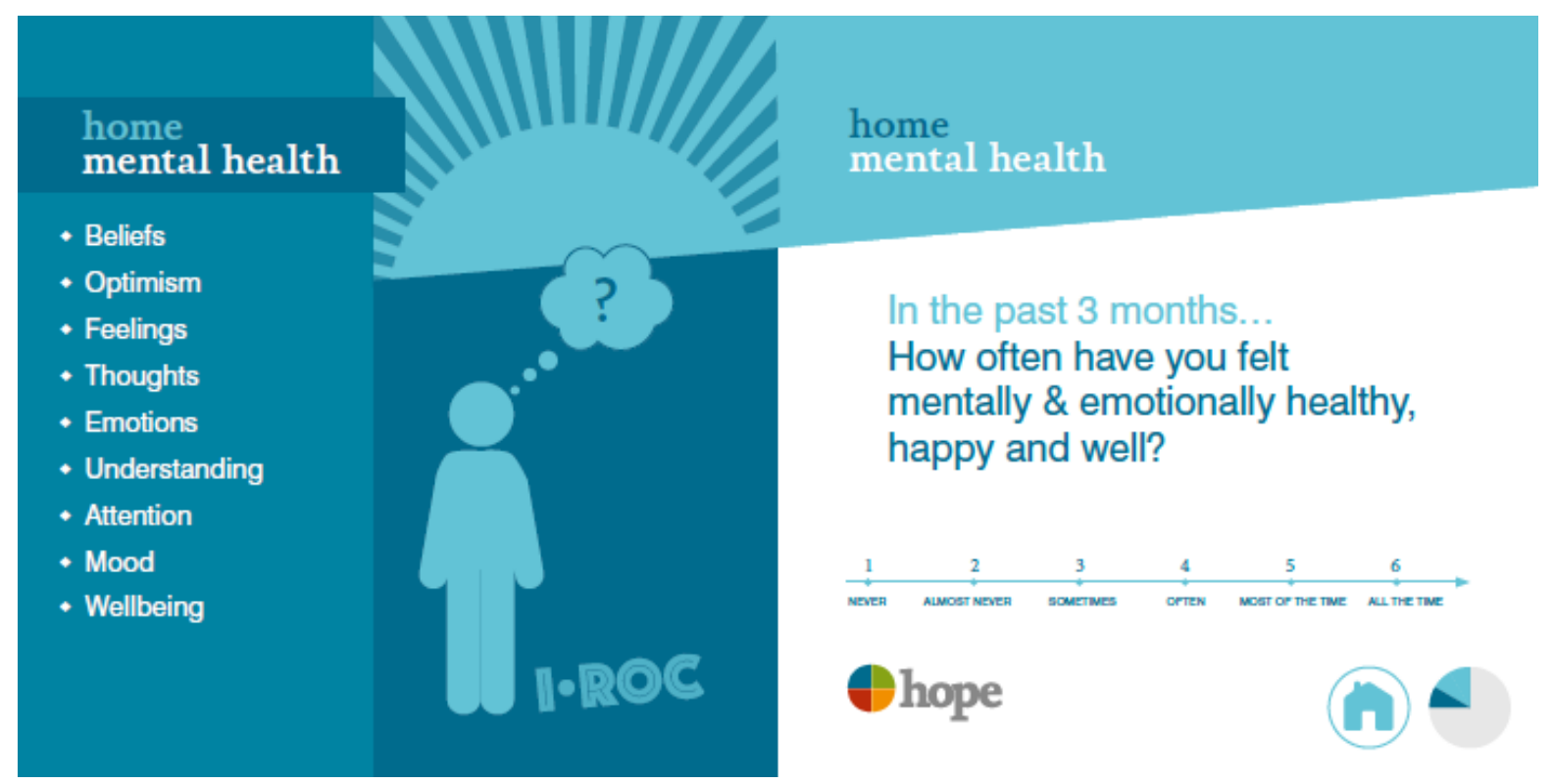

Figure 2: Example page from the I.ROC questionnaire showing the Mental Health item. This demonstrates the format for each of twelve questions, which includes colourful graphics and a list of prompt words 